\title{
Inherited Disorders of Neurotransmitters: Classification and Practical Approaches for Diagnosis and Treatment
}

\author{
Heiko Brennenstuhl ${ }^{1}$ Sabine Jung-Klawitter ${ }^{1}$ Birgit Assmann ${ }^{1}$ Thomas Opladen ${ }^{1}$ \\ ${ }^{1}$ Division of Neuropediatrics and Metabolic Medicine, Department of \\ General Pediatrics, University Children's Hospital Heidelberg, \\ Heidelberg, Germany \\ Address for correspondence Prof. Dr. Thomas Opladen, MD, Division \\ of Neuropediatrics and Metabolic Medicine, Department of General \\ Pediatrics, Im Neuenheimer Feld 430, D-69120 Heidelberg, Germany \\ (e-mail: thomas.opladen@med.uni-heidelberg.de).
} Neuropediatrics 2019;50:2-14.

\begin{abstract}
Neurotransmitter deficiencies are rare neurological disorders with clinical onset during childhood. The disorders are caused by genetic defects in the enzymes involved in synthesis, degradation, or transport of neurotransmitters or by defects in the cofactor biosynthesis such as tetrahydrobiopterin $\left(\mathrm{BH}_{4}\right)$. With the newly described DNAJC12 deficiency, a chaperon-associated neurotransmitter disorder, the pathophysiological spectrum has been broadened. All deficiencies result in a lack of monoamine neurotransmitters, especially dopamine and its products, with a subset leading to decreased levels of serotonin. Symptoms can occur already in the neonatal period.

Keywords

- inherited monoamine neurotransmitter deficiency

- pterin synthesis defect

- pediatric movement disorders

- parkinsonism

- dystonia

- L-dopa Classical signs are hypotonia, movement disorders, autonomous dysregulations, and impaired development. Diagnosis depends on quantitative detection of neurotransmitters in cerebrospinal fluid, since peripheral markers in blood or urine are less reliable. Treatment is based on supplementation of the missing neurotransmitter precursors or restoring deficient cofactors for endogenous enzymatic synthesis. In recent years, knowledge about this orphan group of diseases increased substantially among clinicians. However, the difficult task of integrating clinical symptoms and laboratory values still leads to a critical delay in diagnosis and therapy for patients. This review aims at enhancing the understanding of neurotransmitter disorders and should help practicing clinicians to choose useful diagnostic steps on the way to a valid diagnosis.
\end{abstract}

\section{Introduction}

Brain function depends on neuronal connections in circuits, which range in scale from small local neuronal groups to longdistance projections. Neurons can function in more than one circuit and communicate with thousands of other neurons through synapses. In a single human brain, there are roughly more than 100 trillion synapses. ${ }^{1}$ The classical synaptic organization consists of a pre-synaptic neuron which, upon stimulation by an electrical impulse, releases chemical substances ("neurotransmitter") stored in the axon from vesicles into the synaptic cleft. The neurotransmitter binds to specific receptors located on the postsynaptic membrane of

received

May 2, 2018

accepted after revision

August 22, 2018

published online

October 29, 2018

the following neuron or cell. The binding changes the electrical activity of the postsynaptic neuron, which in turn leads to further interneuron communication. Subsequently, the stimulus is terminated by degradation or re-uptake of the neurotransmitter into the pre-synaptic cell. Synaptic connections forming neuronal circuitries are highly plastic, constantly respond to stimulation, and adapt to a changing environment.

The umbrella term "neurotransmitter" subsumes different types of chemical substances involved in synaptic transmission from cell to cell within the central(CNS) and peripheral nervous system (PNS). Neurotransmitters are synthesized in the neuron and stored within vesicles, are essential for intercellular

(c) 2019 Georg Thieme Verlag KG Stuttgart · New York
DOI https://doi.org/ 10.1055/s-0038-1673630. ISSN 0174-304X. 
communication, and lay the foundation of basic and complex biological functions, including muscular movement as well as neuropsychological development. ${ }^{2}$ Neurotransmitters can be grouped according to their chemical structure into amino acid transmitters (glycine, glutamate and $\gamma$-aminobutyric acid [GABA]), monoamines/biogenic amine transmitters (with the subgroup of catecholamines norepinephrine, epinephrine, and dopamine as well as serotonin), and neuropeptides, classified as short proteins or polypeptides (for example, the hypothalamic hormones oxytocin and vasopressin or orexins). Atypical neurotransmitters have either unusual chemical properties or are less extensively studied and understood. They include the purinergic neurotransmitters adenosine and adenosine triphosphate (ATP), endogenous cannabinoids and opioids, diffusible gases-like nitric oxide (NO) and carbon monoxide (CO) and families of neurotrophic factors and cytokines, and others. ${ }^{1}$

Inherited disorders of neurotransmitters are rare metabolic diseases caused by impaired biosynthesis, breakdown or transport of neurotransmitters, or of essential cofactors in their biosynthesis, such as tetrahydrobiopterin $\left(\mathrm{BH}_{4}\right)$. They result in a variety of clinical presentations ranging from lateonset moderate movement disorders to early-onset lethal encephalopathies. $^{2}$

Clinical symptoms occurring in patients with inherited disorders of monoamine and pterin metabolism often overlap with features seen in other neurological syndromes, such as cerebral palsy or epileptic encephalopathies, which partly results in significant delayed diagnosis. ${ }^{3}$ Conventional and functional brain imaging studies are typically normal. Since tetrahydrobiopterin $\left(\mathrm{BH}_{4}\right)$ is the essential cofactor not only for tyrosine hydroxylase (TH) and tryptophan hydroxylases (TPH) but also for phenylalanine hydroxylase (PAH), hyperphenylalaninemia (HPA) can be present already in newborn screening (NBS), guiding the way to diagnosis. Differential diagnosis is essentially based upon clinical assessment, blood tests (plasma and dried blood spots [DBS]), urine sampling, and cerebrospinal fluid (CSF) investigation. Correct handling of the specimen to avoid preanalytical errors is crucial as is the final interpretation of the analyses with regard to age-adjusted reference values.

This review will focus on primary disorders of monoamine synthesis, transport, and breakdown. It summarizes the current knowledge on diagnostic tools, discusses rational treatment approaches, and gives an overview on new model systems for basic research on neurotransmitter-related disorders.

\section{Primary Monoamine Neurotransmitter Disorders}

\section{Monoamine and Pterin Metabolism}

The term "monoamine neurotransmitter" refers to a group of signaling molecules derived from aromatic amino acids. This group includes the catecholamines dopamine, adrenalin, and noradrenalin which are synthesized in dopaminergic and noradrenergic neurons. Synthesis starts with hydroxylation of L-phenylalanine and L-tyrosine by the $\mathrm{BH}_{4}$-dependent $\mathrm{PAH}$ in the liver and $\mathrm{TH}$ in the adrenal gland and pre-synaptic neurons, respectively, followed by decarboxylation of L-Dopa to dopamine by aromatic amino acid decarboxylase (AADC). In noradrenergic neurons and the adrenal medulla, dopamine- $\beta$-hydroxylase $(D \beta H)$ catalyzes the conversion of dopamine to noradrenalin. In a similar fashion, TPH converts Ltryptophan to 5-hydroxytryptophan (5-HTP) which is then decarboxylated to its active metabolite serotonin by AADC. The role of DNAJC12, a heat shock co-chaperone of the HSP40 family, still needs to be elucidated. While an interaction with PAH has been identified, the suspected influence on $\mathrm{TH}$ and TPH is based on in silico studies (-Fig. 1). ${ }^{4,5}$

$\mathrm{BH}_{4}$ is an essential cofactor for $\mathrm{PAH}, \mathrm{TH}$, and TPHs. In addition, it plays a crucial role in the formation of nitric oxide by nitric oxide synthases (NOS). ${ }^{6}$ It is synthesized from GTP in the following three distinct steps: (1) GTP cyclohydrolase I (GTPCH) converts GTP to 7,8-dihydroneopterin triphosphate $\left(\mathrm{BH}_{2}\right)$ which represents the rate-limiting step in $\mathrm{BH}_{4}$ synthesis; (2) 6-pyruvoyltetrahydropterin synthase (PTPS) catalyzes the conversion of $\mathrm{BH}_{2}$ to 6-pyruvoyltetrahydropterin; and the last step is catalyzed by (3) sepiapterin reductase (SR) via NADPH-dependent reduction of 6-pyruvoyltetrahydropterin to $\mathrm{BH}_{4}$ (- Fig. 1).

Primary monoamine neurotransmitter disorders can thereby be clustered into five distinct subgroups: (1) disorders of $\mathrm{BH}_{4}$ synthesis or recycling with or without hyperphenylalaninemia, (2) primary enzyme defects in monoamine biosynthesis, (3) monoamine catabolism disorders (4) monoamine transporter defects, and (5) chaperon-associated disorders (-Table $\mathbf{1}$ ).

\section{$\mathrm{BH}_{4}$ Cofactor Deficiencies without Hyperphenylalaninemia}

\section{Autosomal Dominant GTPCH I Deficiency (Segawa Disease, Dopa-Responsive Dystonia, DYT5a, DYT| PARK-GCH1) 7}

A deficiency of GTPCH I results in reduced $\mathrm{BH}_{4}$ availability, and subsequently, because of its role as the cofactor for TH and TPH, in decreased levels of dopamine and serotonin. With an incidence of 0.5 per 100.000 people, it is a rare condition caused by dominant mutations in the GCH1 gene. ${ }^{8,9}$ The same mutation in GCH1 can cause a wide phenotypic spectrum. ${ }^{10}$ Key symptoms usually present within the first decade of life revealing dystonia of the lower extremities that asymmetrically progresses to the other limbs. Symptoms can show a circadian fluctuation with worsening during the day and improvement of the symptoms after sleep. 8,11 "Parkinsonian" symptoms such as tremor, bradykinesia, and impaired fine motor skills can be present, especially evolving later in the course due to insufficient treatment. ${ }^{12}$ Neuropsychiatric manifestations such as sleep disturbance, anxiety, or depression are more and more included in the clinical phenotype of Segawa disease, yet, intellectual development is affected only in a small subset of patients. ${ }^{13}$ Levodopa/carbidopa supplementation drastically improves, often even reconstitutes motor function, thereby having therapeutic and diagnostic value. Clinical heterogeneity and resemblance to disorders such as cerebral palsy often substantially delays diagnosis of GTPCH deficiency (GTPCH-D). ${ }^{14}$ However, long-term prognosis correlates with early diagnosis and treatment initiation. ${ }^{15}$ 


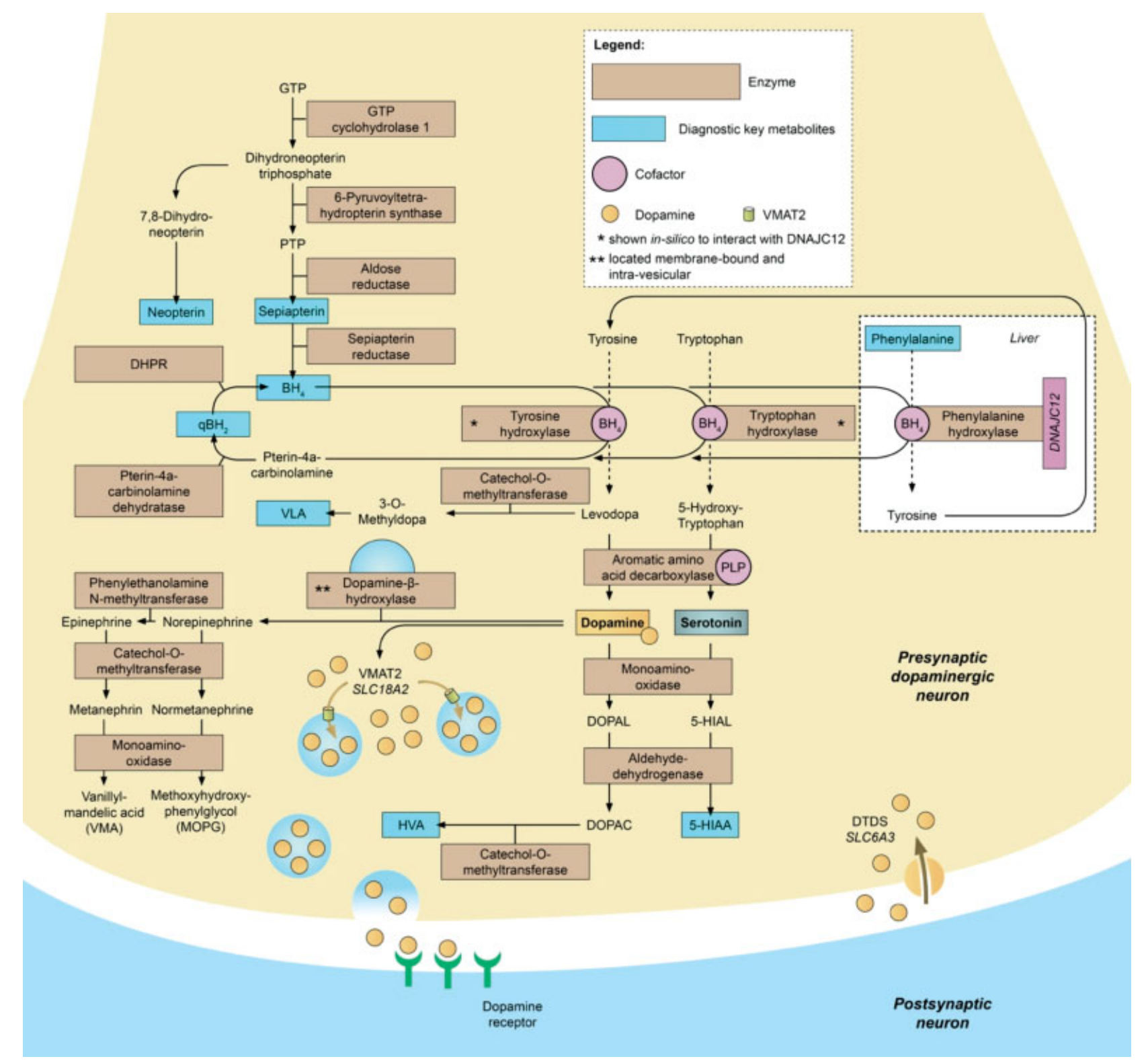

Fig. 1 Pathways of neurotransmitter and biopterin synthesis, degradation, and recycling. 5-HIAA, 5-hydroxyindoleacetic acid; 5-HIAL, 5hydroxyindoleacetaldehyde; $\mathrm{BH}_{4}$, tetrahydrobiopterin; DHPR, dihydropterine reductase; DOPAC, 3,4-dihydroxyphenylacetic acid; DOPAL, 3,4dihydroxyphenylacetaldehyde; DTDS, dopamine transport deficiency syndrome; GTP, guanosine-5'-triphosphate; HVA, homovanillic acid; MOPG, methoxylhydroxyphenylglycol; PLP, pyridoxal 5'-phosphate; PTP, 6-pyruvoyltetrahydropterin; qBH2, quinonoid dihydrobiopterin; VLA, vanillyllactic acid; VMA, vanillylmandelic acid; VMAT 2, vesicular monoamine transporter

\section{Sepiapterin Reductase Deficiency (DYT/PARK-SPR)}

SR deficiency is a very rare autosomal-recessive disorder, caused by mutations in the SPR gene. ${ }^{16}$ So far, 16 mutations in $\sim 50$ patients suffering from SR deficiency (SR-D) have been published. ${ }^{17,18}$ Onset of the disease is usually during early childhood starting from 7 months of age. Symptoms can change over time. The early phenotype includes axial hypotonia, developmental delay of motor functions, and psychiatric symptoms such as increased irritability, behavioral problems, and oculogyric crises. ${ }^{19,20}$ Later, the phenotype changes toward dystonia with apparent circadian rhythm. ${ }^{21}$ In contrast to GTPCH-D, the vast majority of SR-D patients show signs of cognitive learning disabilities. ${ }^{17,22}$ Recently, endocrinological disturbances such as hypoglycemia and growth-hormone deficiency were identified as early symptoms of dopamine depletion in SR-D. ${ }^{23}$ Diagnosis of these disorders may be challenging as early signs may be nonspecific and mimic cerebral palsy. In infants, dystonic spasms and oculogyric crises are often misinterpreted as epileptic activity resulting in frequent delayed or misdiagnoses. ${ }^{17}$ Since phenylalanine (PHE) levels are normal in NBS, diagnosis of SR-D relies on CSF neurotransmitter analysis typically revealing low homovanillic acid (HVA) and 5-hydroxyindoleacetic acid (5-HIAA) with elevated concentrations of sepiapterin and $\mathrm{BH}_{2}$ (or total biopterin). Urine sepiapterin excretion can serve as a peripheral diagnostic marker for sepiapterin deficiency. ${ }^{24}$ This, however, 
Table 1 Overview of the treatment approach of selected inherited neurotransmitter disorders

\begin{tabular}{|c|c|c|c|c|}
\hline Disorder & $\begin{array}{l}\text { Enzyme/protein } \\
\text { deficiency }\end{array}$ & $\begin{array}{l}\text { OMIM/ } \\
\text { Orpha\# }\end{array}$ & Inheritance & Therapy \\
\hline $\begin{array}{l}\text { Co-chaperone } \\
\text { defects }\end{array}$ & DNAJC12 & $\begin{array}{l}\text { OMIM: } \\
606060\end{array}$ & $A R$ & $\begin{array}{l}\mathrm{BH}_{4} 1-10 \mathrm{mg} / \mathrm{kg} / \mathrm{d} \text { titrated according to Phe levels; L-Dopa } \\
\text { starting at } 1 \mathrm{mg} / \mathrm{kg} / \mathrm{d} \text { titrated up to } 10 \mathrm{mg} / \mathrm{kg} / \mathrm{d} \text { combined } \\
\text { with carbidopa in } 4: 1 \text { ratio; consider } 5 \text {-HTP starting at } \\
1 \mathrm{mg} / \mathrm{kg} / \mathrm{d} \text { titrated up to } 10 \mathrm{mg} / \mathrm{kg} / \mathrm{d} \text {. }\end{array}$ \\
\hline \multirow[t]{6}{*}{$\begin{array}{l}\text { Biopterin } \\
\text { synthesis/ } \\
\text { recycling } \\
\text { defects }\end{array}$} & SR & $\begin{array}{l}\text { OMIM: } \\
612716\end{array}$ & $A R$ & $\begin{array}{l}\text { L-Dopa starting at } 1 \mathrm{mg} / \mathrm{kg} / \mathrm{d} \text { titrated up to } 10 \mathrm{mg} / \mathrm{kg} / \mathrm{d} \\
\text { combined with carbidopa in } 4: 1 \mathrm{ratio} \text {, 5-HTP starting at } \\
1 \mathrm{mg} / \mathrm{kg} / \mathrm{d} \text { titrated up to } 8 \mathrm{mg} / \mathrm{kg} / \mathrm{d} \text {, consider selegiline } \\
0.03 \text { to } 0.2 \mathrm{mg} / \mathrm{kg} / \mathrm{d}\end{array}$ \\
\hline & AD-GTPCH & $\begin{array}{l}\text { OMIM: } \\
233910\end{array}$ & $A D$ & $\begin{array}{l}\text { L-Dopa starting at } 1 \mathrm{mg} / \mathrm{kg} / \mathrm{d} \text { titrated up to } 10 \mathrm{mg} / \mathrm{kg} / \mathrm{d} \\
\text { combined with carbidopa in 4:1 ratio, }\end{array}$ \\
\hline & AR-GTPCH & $\begin{array}{l}\text { OMIM: } \\
233910\end{array}$ & $A R$ & $\begin{array}{l}\text { L-Dopa starting at } 1 \mathrm{mg} / \mathrm{kg} / \mathrm{d} \text { titrated up to } 10 \mathrm{mg} / \mathrm{kg} / \mathrm{d} \\
\text { combined with carbidopa in } 4: 1 \mathrm{ratio}, 5-\mathrm{HTP} \text { starting at } \\
1 \mathrm{mg} / \mathrm{kg} / \mathrm{d} \text { titrated up to } 6 \mathrm{mg} / \mathrm{kg} / \mathrm{d}, \mathrm{BH}_{4} 1 \text { to } 10 \mathrm{mg} / \mathrm{kg} / \mathrm{d} \\
\text { titrated according to Phe levels }\end{array}$ \\
\hline & PTPS & $\begin{array}{l}\text { OMIM: } \\
261640\end{array}$ & $A R$ & $\begin{array}{l}\text { L-Dopa starting at } 0.5-1 \mathrm{mg} / \mathrm{kg} / \mathrm{d} \text { titrated up to } 10 \mathrm{mg} / \mathrm{kg} / \mathrm{d} \\
\text { combined with carbidopa in } 4: 1 \mathrm{ratio}, 5-\mathrm{HTP} \text { starting at } \\
1 \mathrm{mg} / \mathrm{kg} / \mathrm{d} \text { titrated up to } 8 \mathrm{mg} / \mathrm{kg} / \mathrm{d}, \mathrm{BH}_{4} 1 \text { to } 10 \mathrm{mg} / \mathrm{kg} / \mathrm{d} \\
\text { titrated according to Phe levels }\end{array}$ \\
\hline & DHPR & $\begin{array}{l}\text { OMIM: } \\
261630\end{array}$ & $A R$ & $\begin{array}{l}\text { L-Dopa starting at } 0.5-1 \mathrm{mg} / \mathrm{kg} / \mathrm{d} \text { titrated up to } 10 \mathrm{mg} / \mathrm{kg} / \mathrm{d} \text {, } \\
5 \text {-HTP starting at } 3 \mathrm{mg} / \mathrm{kg} / \mathrm{d} \text { titrated up to } 11 \mathrm{mg} / \mathrm{kg} / \mathrm{d} \text {, } \\
\text { phenylalanine level control only by dietary measures, folinic } \\
\text { acid } 10-20 \mathrm{mg} / \mathrm{d}\end{array}$ \\
\hline & PCD & $\begin{array}{l}\text { OMIM: } \\
264070\end{array}$ & $A R$ & $\begin{array}{l}\text { Consider } \mathrm{BH}_{4} \text { titrated according to Phe levels, early screening } \\
\text { for diabetes }\end{array}$ \\
\hline \multirow[t]{2}{*}{$\begin{array}{l}\text { Primary } \\
\text { neurotransmitter } \\
\text { synthesis defects }\end{array}$} & $\mathrm{TH}$ & $\begin{array}{l}\text { OMIM: } \\
605407\end{array}$ & $A R$ & $\begin{array}{l}\text { L-Dopa starting at } 0.5-1 \mathrm{mg} / \mathrm{kg} / \mathrm{d} \text { titrated up to } 10 \mathrm{mg} / \mathrm{kg} / \mathrm{d} \\
\text { combined with carbidopa in } 4: 1 \text { ratio, selegiline } \\
0.1-0.4 \mathrm{mg} / \mathrm{kg} / \mathrm{d} \text { (max. dose } 10 \mathrm{mg} / \mathrm{d} \text { ) }\end{array}$ \\
\hline & AADC & $\begin{array}{l}\text { OMIM: } \\
608643\end{array}$ & $A R$ & $\begin{array}{l}\text { Dopamine agonists: pramipexole BASE } 5-10 \mu \mathrm{g} / \mathrm{kg} / \mathrm{d} \\
\text { (max. } 75 \mathrm{\mu g} / \mathrm{kg} / \mathrm{d}) \text {, ropinirole } 0.25 \mathrm{mg} / \mathrm{d}(\mathrm{max} .24 \mathrm{mg} / \mathrm{d}) \text {, } \\
\text { transdermal rotigotine } 2 \mathrm{mg} / \mathrm{d} \text {, increased weekly up to } \\
8 \mathrm{mg} / \mathrm{d} \text {, bromocriptine } 0.1 \mathrm{mg} / \mathrm{kg} / \mathrm{d} \text { up to } 0.5 \mathrm{mg} / \mathrm{kg} / \mathrm{d} \\
\text { MAO inhibitors: selegiline } 0.1 \mathrm{mg} / \mathrm{kg} / \mathrm{d} \text { increase every two } \\
\text { weeks up to } 0.3 \mathrm{mg} / \mathrm{kg} / \mathrm{d} \text {, tranylcypromine } 0.1 \mathrm{mg} / \mathrm{kg} / \mathrm{d} \\
\text { increase every two weeks up to } 30 \mathrm{mg} / \mathrm{d} \\
\text { Co-factors: pyridoxine } 100 \text { to } 200 \mathrm{mg} / \mathrm{d} \text {, pyridoxal } \\
\text { 5'-phosphate } 100 \text { to } 200 \mathrm{mg} / \mathrm{d}\end{array}$ \\
\hline \multirow[t]{2}{*}{$\begin{array}{l}\text { Monoamine } \\
\text { transportopathies }\end{array}$} & $\begin{array}{l}\text { SLC6A3 } \\
\text { (DTDS) }\end{array}$ & $\begin{array}{l}\text { OMIM: } \\
613135\end{array}$ & $A R$ & $\begin{array}{l}\text { Pramipexole BASE } 5 \text { to } 40 \mu \mathrm{g} / \mathrm{kg} / \mathrm{d} \text {, ropinirole } 0.5 \text { to } 4 \mathrm{mg} / \mathrm{d} \text {, } \\
\text { transdermal rotigotine } 6 \mathrm{mg} / \mathrm{kg} / \mathrm{d}\end{array}$ \\
\hline & $\begin{array}{l}\text { SLC18A2 } \\
\text { (VMAT2) }\end{array}$ & $\begin{array}{l}\text { Orpha: } \\
352649\end{array}$ & $A R$ & Pramipexole BASE 5 to $40 \mu \mathrm{g} / \mathrm{kg} / \mathrm{d}$ \\
\hline \multirow{2}{*}{$\begin{array}{l}\text { Monoamine } \\
\text { catabolism } \\
\text { disorders }\end{array}$} & MAOA/MAOB & $\begin{array}{l}\text { OMIM: } \\
309850\end{array}$ & X-linked & $\begin{array}{l}\text { SSRI have shown beneficial effect in mice, no data for humans } \\
\text { available }\end{array}$ \\
\hline & $\mathrm{DBH}$ & $\begin{array}{l}\text { OMIM: } \\
609312\end{array}$ & $A R$ & $\begin{array}{l}\text { Droxidopa used in adults as } 100 \mathrm{mg} 3 \times \text { daily to a maximum } \\
\text { dose of } 600 \mathrm{mg} 3 \times \text { daily; no data for pediatric use available }\end{array}$ \\
\hline
\end{tabular}

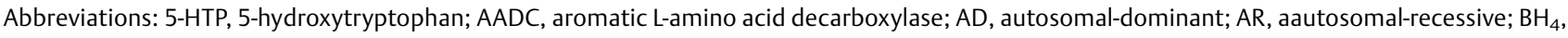
tetrahydrobiopterin; DBH, dopamine $\beta$-hydroxylase; DHPR, dihydropterine reductase; DTDS, dopamine transport deficiency syndrome; GTPCH, guanosine-5'-triphosphate cyclohydrolase; MAO A/B, monoamine oxidase A/B; n.s., non-specific changes; PCD, pterin-4a-carbinolamine dehydratase; PTPS, 6-pyruvoyltetrahydropterin synthase; SR, sepiapterin reductase; SSRI, selective serotonin reuptake inhibitor; TH, tyrosine hydroxylase; VMAT2, vesicular monoamine transporter 2.

Please note: The dosages given are the range which is usually applied and has been published. In individual patients, some adaptations and variations might be reasonable. For example, in autosomal dominant GTPCH1 deficiency, usually between 4 and $7 \mathrm{mg} / \mathrm{kg} / \mathrm{d}$ of L-dopa are sufficient to stop the movement disorder. In these cases, L-dopa should not be increased further. On the other end of the spectrum in severe dopamine deficiency, patients may not tolerate more than 5 to $7 \mathrm{mg} / \mathrm{kg} /$ day. Some more hints how to decide about dosage and pace of increments are given in the text.

${ }^{a}$ Dosing for sublingual selegiline preparation can differ. 
necessitates special techniques since sepiapterin is not detected with the standard ultraviolet (UV) absorption wavelength.

The cornerstone of treatment is supplementation of neurotransmitter precursors L-dopa and 5-HTP combined with inhibition of peripheral decarboxylation (e.g., carbidopa). Carbidopa helps to increase the amount of available L-dopa in the CNS by blocking peripheral decarboxylation and should be used in a 4:1 (or 10:1) ratio to L-dopa. Additional agents including serotonin re-uptake inhibitors (SSRI), dopamine agonists, monoamine oxidase (MAO) inhibitors dopamine/noradrenaline re-uptake inhibitors, and melatonin have been shown to have some benefit in individual cases. ${ }^{17}$

\section{$\mathrm{BH}_{4}$ Cofactor Deficiencies with Hyperphenylalaninemia}

\section{Autosomal Recessive GTPCH I Deficiency (DYT/PARK- GCH1)}

Compound heterozygous or homozygous mutations in $\mathrm{GCH} 1$ lead to a more severe form of GTPCH-D, which usually presents in the early neonatal period showing a complex neurological phenotype. Truncal hypotonia, neonatal rigidity, dystonia parkinsonism features, and oculogyric crisis can be first clinical signs. HPA is present in most cases and can be detected in NBS. However, this important diagnostic marker is not mandatory for this form of GTPCH-D. ${ }^{25,26}$

Treatment of AR-GTPCH-D relies on supplementation of Ldopa/carbidopa, which should be titrated very slowly (-Table 1). Required doses to achieve good motor function are usually much higher in AR-GTPCH-D than in AD-GTPCHD. Administration of 5-HTP has been proven to increase serotonin levels and reduce psychiatric symptoms. The use of $\mathrm{BH}_{4}$ is widely discussed, since it only affects the HPA, while leaving the central dopaminergic pathway unaffected. Furthermore, high doses of $\mathrm{BH}_{4}$ are needed to achieve adequate levels in CSF and symptom-relief is only mild. Therefore, currently we do not support the use of $\mathrm{BH}_{4}$ in AR-GTPCH-D to improve dopaminergic symptoms, but it can be applied to control HPA.

\section{6-Pyruvoyltetrahydropterin Synthase Deficiency (DYT/PARK-PTS)}

PTPS deficiency (PTPS-D) caused by mutations in the PTPS gene represents the most frequent disorder of $\mathrm{BH}_{4}$ synthesis accompanied by HPA. ${ }^{3}$ Residual enzyme activity creates a variety of phenotypes ranging from mild forms with normal neurological development to severe forms with hypotonia, a complex movement disorder dominated by dystonia or dystonia parkinsonism, epileptic seizures, and mental retardation. ${ }^{27-29}$ High levels of plasma phenylalanine are usually detected in NBS leading to early diagnosis, ${ }^{26}$ thereby making early treatment a key strategy to preserve neurological function.

Again, supplementation of neurotransmitter precursors with inhibitors of peripheral decarboxylation is indispensable in most cases. $\mathrm{BH}_{4}$ supplementation can restore hepatic PAH function and achieve normal blood phenylalanine levels. Single PTPS-D patients might benefit from $\mathrm{BH}_{4}$ monotherapy, yet again, high doses (up to $30 \mathrm{mg} / \mathrm{kg} / \mathrm{d}$ ) of peripherally administered $\mathrm{BH}_{4}$ are necessary to achieve adequate concentrations in the CNS. ${ }^{3}$

\section{Dihydropteridine Reductase Deficiency (DYT/PARK- QDPR)}

During hydroxylation of amino acids by amino acid hydroxylases, $\mathrm{BH}_{4}$ is oxidized to pterin-4a-carbinolamine. The subsequent regeneration of $\mathrm{BH}_{4}$ by dihydropteridine reductase (DHPR) and pterin-4a-carbinolamine dehydratase (PCD) ensures a continuous supply of reduced cofactor and prevents accumulation of harmful metabolites (-Fig. 1). ${ }^{30}$

Dihydropteridine reductase deficiency (DHPR-D) is caused by mutations in the QDPR gene. ${ }^{16}$ Although the primary $\mathrm{BH}_{4}$ biosynthesis pathway is intact, the clinical course is usually worse compared with primary $\mathrm{BH}_{4}$ synthesis defects and can be associated with poor prognosis. ${ }^{31,32}$ Accumulating 7,8dihyrobiopterin and subsequent blockage of catecholamine and serotonin production in the central nervous system, uncoupled NOS, and 5-methyltetrahydrofolate (5-MTHF) formation contribute to the pathophysiology. ${ }^{28,33-35}$

DHPR-D patients show early symptoms including feeding problems during neonatal period, hypersalivation, microcephaly, and developmental delay. During infancy, truncal hypotonia with a complex movement disorder with predominating dystonia parkinsonism and tremor, as well as seizures often contribute to the phenotype. ${ }^{3}$ HPA in NBS should lead to further assessment of DHPR activity in blood cells. In DHPR-D, CSF analysis can reveal reduced concentrations of serotonin and dopamine metabolites HVA and 5HIAA as well as low levels of 5-MTHF. Genetic testing for QDPR should be used to confirm diagnosis.

Treatment is based on neurotransmitter precursor replacement similar to other $\mathrm{BH}_{4}$ biosynthesis defects. In contrast, $\mathrm{BH}_{4}$ supplementation is still controversial since an increased accumulation of potentially harmful 7,8-dihydrobiopterin as a consequence of $\mathrm{BH}_{4}$ treatment has been discussed. Therefore, currently only a phenylalanine-restricted diet is recommended to handle HPA associated with DHPR-D. ${ }^{36}$ Low CSF folate levels should be corrected by administration of folinic acid, which has been shown to increase L-dopa levels in the brain. ${ }^{37}$ After the beginning of treatment, follow-up visits should initially be done every 3 to 6 months and later at least once per year including clinical evaluation and neuropsychological assessment, weight-related dosage adjustment and determination of biogenic amines, pterins, and folate metabolites in $\mathrm{CSF}^{3}$

\section{Pterin-4a-carbinolamine Dehydratase deficiency}

$\mathrm{PCD}$ is the second enzyme in $\mathrm{BH}_{4}$ regeneration catalyzing the dehydration of pterin-4a-carbinolamine to quinoid dihydropteridine which rearranges nonenzymatically to 7,8dihydrobiopterin. PCD deficiency (PCD-D) is based on mutations in PCBD1 and results in mild HPA in NBS. Diagnosis can be confirmed by high urine levels of 7-biopterin (primapterin). ${ }^{38}$ The absence of severe neurological symptoms is a main characteristic of this disease. PCD deficiency is predominantly considered to be a transient and benign form of 
HPA more than a neurotransmitter disorder. While in the past, treatment consisted of dietary measures, today $\mathrm{BH}_{4}$ supplementation is used as a therapeutic strategy.

Interestingly, PCD is described to be a dimerization cofactor for hepatocyte nuclear factor $1(\mathrm{HNF} 1) .{ }^{39}$ Mutations in PCBD1 cause reduced transcriptional activity of HNF1 and are associated with impaired development of liver and pancreatic cells causing early-onset diabetes. ${ }^{40,41}$

\section{Primary Enzyme Defects in Monoamine Biosynthesis}

\section{Tyrosine hydroxylase Deficiency (Dopa-Responsive Dystonia, DYT5b, DYT/PARK-TH)}

TH deficiency (TH-D) is based on mutations in the TH gene with unknown prevalence. TH catalyzes the rate-limiting step of dopamine synthesis. Malfunction of the enzyme results in isolated catecholamine deficiency. The clinical presentation resembles those seen in disorders of $\mathrm{BH}_{4}$ biosynthesis: dystonia parkinsonism, ptosis, oculogyric crises, as well as nonspecific features such as developmental delay and signs of autonomic dysfunction. ${ }^{42}$ Patients can be grouped into a more frequent type $A$ (mild-to-moderate phenotype) and a type B (severe form) according to the severity of the clinical features showing a continuum in between. ${ }^{43}$ While type $A$ patients present with the above-mentioned symptoms, type $B$ patients usually show early neonatal onset encephalopathy, growth retardation, a more hypokinetic rigid than dystonic movement disorder and severe developmental delay. ${ }^{42,43}$

Diagnosis is based upon low CSF concentrations of HVA and 3-methoxy-4-hydroxyphenylglycol (MHPG), with a concurrent normal concentration of 5-HIAA and a low HVA/5-HIAA ratio. CSF HVA levels are helpful in determining L-dopa responsiveness and can in addition to the clinical symptoms be used as follow-up marker under L-dopa/carbidopa supplementation. However, there is no clear recommendation for CSF follow-up investigations. Instead clinical assessment with standardized test forms, for example Gross Motor Function Measure (GMFM), can be used to assess therapeutic success. ${ }^{42,44}$

Therapeutic L-dopa/carbidopa replacement is the key treatment in TH-D. TH-D patients are highly sensitive to Ldopa treatment. The more pronounced the dopaminergic deficiency is, the more likely even small doses of L-dopa can lead to overstimulation causing tremendous side effects, such as dyskinesia, nausea, and vomiting. This phenomenon could lead to the incorrect assumption that L-dopa exhibits direct toxicity. In patients presenting symptoms of hyperresponsiveness, the dosage of $\mathrm{L}$-dopa should only be lowered until vanishing of side effects can be seen. Patients with poor response to L-dopa/carbidopa or important fluctuations (in general, patients with severe enzyme deficiency) can benefit from additional treatment with MAO inhibitors such as the MAO-B inhibitor selegiline or dopaminergic receptor agonists (-Table 1). ${ }^{45,46}$

\section{Aromatic L-Amino Acid Decarboxylase Deficiency}

AADC deficiency (AADC-D) results from mutations of the $D D C$ gene. AADC-D incidence is unknown; however, there is a higher prevalence in the Asian population. ${ }^{47}$ The clinical phenotype of AADC deficiency is based on a combined absence or reduction of serotonin and catecholamines. Symptoms can hardly be distinguished from other neurotransmitter deficiencies and pterin synthesis defects, yet autonomous dysregulation can be seen more often in AADC-D than in the aforementioned disorders. Many patients present with temperature instability, sweating, nasal congestion, insomnia, or irritability. ${ }^{48-50}$ Developmental delay and progressive extrapyramidal movement disorder with predominating dystonia parkinsonism are seen frequently in this patient group. ${ }^{51}$ In the CSF, HVA, and 5-HIAA show dramatically decreased concentrations combined with elevated levels of 3-orthomethyldopa (3-OMD, a product of L-dopa methylation), levodopa, and 5HTP. Due to impaired catecholamine synthesis, the specific degradation metabolite and intermediate vanillyl acetate can be found by analysis of organic acids in urine. It should be noted that pyridoxine 5'-phosphate deficiency (PNPO) leads to a deficiency of pyridoxal 5'-phosphate which is a co-factor of AADC and therefore can mimic the metabolic profile of AADCD with low urinary vanillylactate. ${ }^{49,52}$ Measurement of catecholamine concentration in urine is not useful since the kidney usually displays high residual AADC enzyme activity leading to normal or elevated levels of urinary dopamine. ${ }^{53}$ A recent publication describes plasma levels of 3-methoxytyrosine (3MT) as a viable biomarker for AADC-D. ${ }^{54}$ Confirmation of the causative enzyme deficiency is best achieved by enzyme activity assay in plasma and helps to distinguish from PNPO deficiency. ${ }^{55}$

For the treatment of AADC-D, a consensus guideline was recently published, nevertheless, treatment response is often disappointing. ${ }^{56}$ First-line treatment consists of dopamine agonists activating postsynaptic dopamine receptors and/or MAO inhibitors preventing the breakdown of dopamine and serotonin, thereby increasing monoamine availability. Pyridoxal phosphate (PLP), the active form of pyridoxine, is a cofactor of $\mathrm{AADC}$ and supplementation might increase the residual activity of the AADC enzyme. ${ }^{56}$ Current clinical trials examine the administration of an adeno-associated virus (AAV) vector containing the human gene for the AADC enzyme into patient's putamen. While preliminary data revealed significant improvements in motor performance, long-term data have to be further evaluated and discussed. ${ }^{57}$ In rare cases with variants present at the L-dopa binding site of $D D C$, a sustained effect of L-dopa was seen. This effect was attributed to a decreased binding affinity of AADC for the substrate, which was overcome by administration of high L-dopa doses. ${ }^{58}$

\section{Disorders of Monoamine Catabolism}

\section{Monoamine Oxidase (MAO-A/MAO-B) Deficiency}

The two isoenzymes monoamine oxidases $A$ and $B$, located in secretory neurotransmitter vesicles, are key enzymes responsible for oxidative deamination of catecholamines, dopamine, serotonin, and several xenobiotics (-Fig. 1). ${ }^{59}$ Both genes for $M A O A$ and $M A O B$ are located at region Xp11.23 making this a rare $\mathrm{X}$-linked condition with unknown prevalence. Whereas isolated MAO-B deficiency does barely reveal a clinical 
phenotype, isolated MAO-A deficiency is associated with mental retardation and severe behavioral abnormalities including repeating aggressive and violent outbursts. ${ }^{60}$ Autonomous dysregulation including flush and diarrhea were reported. ${ }^{61}$ Combined MAO-A and MAO-B deficiency leads to mental retardation, sporadic episodes of hypotonia, stereotypical movements, and epilepsy. ${ }^{62}$

Biochemical features are high levels of blood serotonin and high levels of MAO-A substrates such as normetanephrine and 3-methoxytyramine in urine while products of MAO-A oxidation in CSF including HVA, MHPG, and 5-HIAA show reduced levels. ${ }^{59,63-65}$ Enzymatic measurement of MAO-A activity can be done in dexamethasone-stimulated fibroblasts and for MAO-B in platelets. ${ }^{63,65}$ So far, no specific treatment is available for MAO deficiency. In mouse models, symptomatic treatment with SSRI has been shown to reduce aggressive behavior and might be a feasible option for human treatment. ${ }^{66}$

\section{Dopamine- $\beta$-hydroxylase Deficiency}

Dopamine- $\beta$-hydroxylase Deficiency (DBH-D), encoded by the $D B H$ gene, is a membrane-bound intravesicular enzyme catalyzing the conversion of dopamine to norepinephrine in presynaptic secretory vesicles. DBH deficiency represents a very rare disease with $\sim 20$ cases worldwide. ${ }^{67}$ Malfunction of the enzyme results in decreased sympathetic noradrenergic signaling while parasympathetic signaling remains unaffected. This regulatory imbalance results in syncopal episodes due to profound orthostatic hypotension combined with ptosis and is usually developing during late childhood. ${ }^{67}$ Characterization of $\mathrm{DBH}^{-1-}$ mice pointed toward an effect of DBH function on glucose homeostasis due to reduced sympathetic inhibition of insulin secretion. ${ }^{68}$ The phenotypic spectrum was therefore expanded, when Arnold et al examined a DBH deficient patient with hyperinsulinemia, increased glucose-triggered insulin secretion, and peripheral resistance toward insulin. ${ }^{69}$

Reduced or absent levels of norepinephrine and epinephrine in blood with simultaneously elevated dopamine levels are biochemical findings in DHB-deficient patients. ${ }^{70}$ Droxidopa, a synthetic amino acid precursor of norepinephrine, is shown to cross the blood-brain barrier and can be utilized by AADC to generate dopamine, thereby improving orthostatic hypotension. ${ }^{67}$

Recently, two families with orthostatic hypotension with similar biochemical findings to DBH deficiency, yet normal DBH activity and normal $D B H$ gene, were identified and further characterized. ${ }^{71}$ Genetic analysis revealed biallelic mutations in the CYB561 gene, encoding for cytochrome b561 protein. CYB561 functions as a trans-membrane electron carrier on catecholamine secretory vesicles and maintains the redox state between cytosolic and intravesicular ascorbic acid, which is required by $\mathrm{DBH}$ for proper enzyme functionality. ${ }^{71}$

\section{Monoamine Transporter Defects}

\section{Dopamine Transporter Deficiency Syndrome}

The termination of intercellular communication is a highly orchestrated process. Termination relies on degradation of the neurotransmitter within the synaptic cleft or re-uptake into the presynaptical neuron. This re-uptake is achieved by transmembrane transporter proteins such as solute carrier family 6 encoded by SLC6A3. If dopamine cannot be removed from the synaptic cleft, it accumulates in the synaptic cleft and activates post-synaptic D2 receptors, which first lead to overactivity of dopaminergic signaling (hyperkinesia and sleep disturbance) as well as presynaptic D2 synthesis-regulating autoreceptors (D3), which most probably decreases dopamine synthesis in a negative feedback-loop earlier or later in the course. ${ }^{72}$

Movement disorders develop during early childhood with axial hypotonia and a variable clinical picture which may be predominantly choreatiform, dystonic, or consist of dystonia parkinsonism in the beginning. Over time, hyperkinetic features shift toward parkinsonian symptoms such as tremor, bradykinesia, and hypomimia. Eye movement disorders are often observed and mostly consist of ocular flutter, saccade initiation failure. In some patients, oculogyric crises occur. Neurodevelopmental milestones are hardly achieved; however, cognitive impairment is usually mild compared with motor deficiencies. ${ }^{73,74}$ Besides, dopamine transporter deficiency syndrome (DTDS) of early infancy, a later-onset subtype correlating with higher residual transporter activity, was recently described. This subtype is characterized by juvenileonset parkinsonism with dystonia, progressive bradykinesia, and rigidity with an overall milder disease course. This is most likely based on residual transporter activity hinting toward a substantial genotype-phenotype correlation of DTDS. ${ }^{74}$

Diagnosis can be established by CSF analysis showing a combination of raised levels of HVA with normal 5-HIAA levels, resulting in an increased HVA/5-HIAA ratio ( $>4.0$; refErence range: $1.0-4-0)$ and a normal pterin profile. ${ }^{75}$ Molecular genetic testing for homozygous/compound heterozygous mutations of SLC6A3 confirms the diagnosis. While laboratory findings are similar for the late-onset subtype, clinical prognosis is unclear.

DTDS relies on symptomatic treatment rather than a causative approach. Dopamine agonists showing high affinity to presynaptic autoreceptors, such as pramipexole and ropinirole, are recommended as expert consensus. ${ }^{75}$ Transdermal rotigotine has been shown to improve symptoms in one case. ${ }^{48}$ Dystonia can also be treated with anticholinergic drugs, such as trihexyphenidyl, oral baclofen, or benzodiazepines. Overall, the effect of treatment is less pronounced than in, for example, TH-D or distinct pterin-pathway defects.

\section{Vesicular Monoamine Transporter 2 Deficiency}

Vesicular monoamine transporter 2 (VMAT2) is encoded by the gene SLC18A2 and plays a pivotal role during dopamine loading of presynaptic vesicles. Initially, eight affected individuals from one family have been published revealing symptoms similar to AADC-D with early childhood developmental delay, delayed achievement of developmental goals, axial hypotonia, and oculogyric crises as well as bulbar dysfunction and parkinsonian features developing during early adulthood. ${ }^{76}$ Due to a simultaneous deficiency of catecholamines, autonomic disturbance such as sweating, profuse nasal, and oropharyngeal secretions and postural 
hypotension have been described. Likewise, reduced levels of serotonin lead to psychiatric disturbances, such as insomnia and depression. ${ }^{76}$ CSF findings are not suitable for diagnosis, but patients present low blood serotonin levels. ${ }^{77}$ However, in cases of high clinical suspicion, genetic testing of SLC18A2 is mandatory.

While L-dopa/carbidopa worsened symptoms in VMAT2 deficiency, pramipexole helped to achieve a significant symptom relief with improvement in parkinsonian features and reduced frequency of dystonic attacks. ${ }^{76,78}$

\section{Chaperon-Associated Neurotransmitter Disorders}

\section{DNAJC12}

DNAJC12 encodes a heat shock co-chaperone of the HSP40 family which has been shown to interact with PAH and at least in silico with $\mathrm{TH}$ and $\mathrm{TPH} .{ }^{4,5}$ Recently, biallelic mutations in the DNAJC12 gene have been identified in six individuals of four families with HPA, serotonin and dopamine deficiency and missing mutations in genes encoding enzymes of neurotransmitter synthesis or pterin metabolism. The affected individuals showed a broad spectrum of clinical symptoms including dystonia, speech delay, axial and limb hypertonia, parkinsonism as well as psychiatric features. ${ }^{79}$ Until today, around 20 patients have been described presenting with very mild or even absent neurological symptoms. ${ }^{80}$ An additional phenotype with slowly progressing parkinsonism in the presence of mild intellectual disability and no dystonic features at disease onset in adolescence broadens the spectrum of DNAJC12 mutations. ${ }^{81}$ In all patients, HPA was detected during NBS. Diagnosis for known primary neurotransmitter deficiencies or $\mathrm{BH}_{4}$ metabolism disorders could not be confirmed by standard procedures. CSF pattern in DNACJ12-D shows decreased 5-HIAA and HVA concentrations with normal or elevated levels of biopterin.

Treatment should be initiated early and consists of administration of the monoamine neurotransmitter precursors Ldopa/carbidopa and 5-HTP in combination with $\mathrm{BH}_{4}$ supplementation.

\section{General Remarks to Symptoms Seen in Neurotransmitter Deficiencies}

The inherited dopamine deficiency resembles the most prominent contributor to the clinical phenotype of neurotransmitter deficiencies. Symptoms of the individual dopaminergic defects are primarily depending on the degree of dopamine deficiency. Very mild TH-D may show a "Segawa-like-phenotype," 82 which is usually found in autosomal dominant GTPCH deficiency (with high residual enzyme activity), whereas autosomal recessive (AR) GTPCH deficiency (with low residual enzyme activity) is clinically indistinguishable from other pterin defects-especially in young children. Nevertheless, some features are also found more often or typically according to the underlying biochemical defect. In DHPR-D, for example, microcephaly, intracranial calcifications and epilepsy may complicate the clinical course. $^{83,84}$
The picture of untreated severe dopamine deficiency comprises severe truncal hypotonia in infants with the progressive development of dystonia and parkinsonian features in the limbs as well as oculogyric crises. Dystonia may include myoclonic elements. Autonomous dysregulation can lead to ptosis and miosis, and sometimes distal choreatiform movements (including tongue) or tremor may be seen. Serotonin deficiency manifests in a less obvious manner, but presumably contributes to vegetative symptoms caused by autonomous dysregulation such as, for example, abnormal sweating. In some patients, psychiatric symptoms, such as sleep disturbances and depression, are attributed to serotonin deficiency. However, serotonin deficiency probably also directly contributes to the development of dystonia due to a dysregulation of serotonergic neurotransmission in the dysfunctional basal ganglia network involved in dystonia. ${ }^{85}$-Fig. 2 highlights key symptoms found in children with neurotransmitter deficiencies. Identification of these symptoms in pediatric patients should result in further testing according to the following chapter.

\section{Practical Approaches for Diagnosis and Treatment}

\section{Useful Diagnostic Tools|Algorithms}

Since there is no specific peripheral marker available and since imaging studies typically look normal, diagnosis of neurotransmitter deficiencies relies on determination of distinct neurotransmitters or their respective degradation or precursor products in CSF. Nevertheless, since this specific analysis is limited to very few laboratories worldwide requiring a standardized protocol and pre-analytical measures (including transport on dry ice), any other differential diagnoses in a patient with suspicious muscular hypotonia or movement disorders should be considered before performing a lumbar puncture. In every patient with HPA, dried blood spots should be used for measurement of pterins and DHPR activity. In patients with suspicious clinical presentation and absence of HPA, determination of sepiapterin in urine can be considered. ${ }^{24}$ An elevated prolactin level is one of the few peripheral markers pointing to a central dopaminergic deficiency. However, physical or emotional stress during sample collection can result in falsely high prolactin levels and therefore might be misinterpreted (e.g., due to distressed children in a hospital setting). Whole blood serotonin can be another useful peripheral marker and has been documented to be diminished in $\mathrm{BH}_{4}$ disorders, AADC-D, SR$\mathrm{D}$, and VMAT2. ${ }^{77,86}$ Again, the sensitivity of this parameter has not been documented in a greater series of patients.

CSF samples are still gold standard for the diagnostics of neurotransmitter disorders. Samples must be collected in close cooperation with the respective metabolic laboratory. CSF should be collected through a standardized lumbar puncture protocol under best clinical conditions. Samples must be acquired in adequate amounts and frozen immediately and should be stored at $-70^{\circ} \mathrm{C}$, on dry ice or in liquid nitrogen to preserve the metabolites. Certain pterin species are unstable and very sensitive to UV-light; thus, samples 


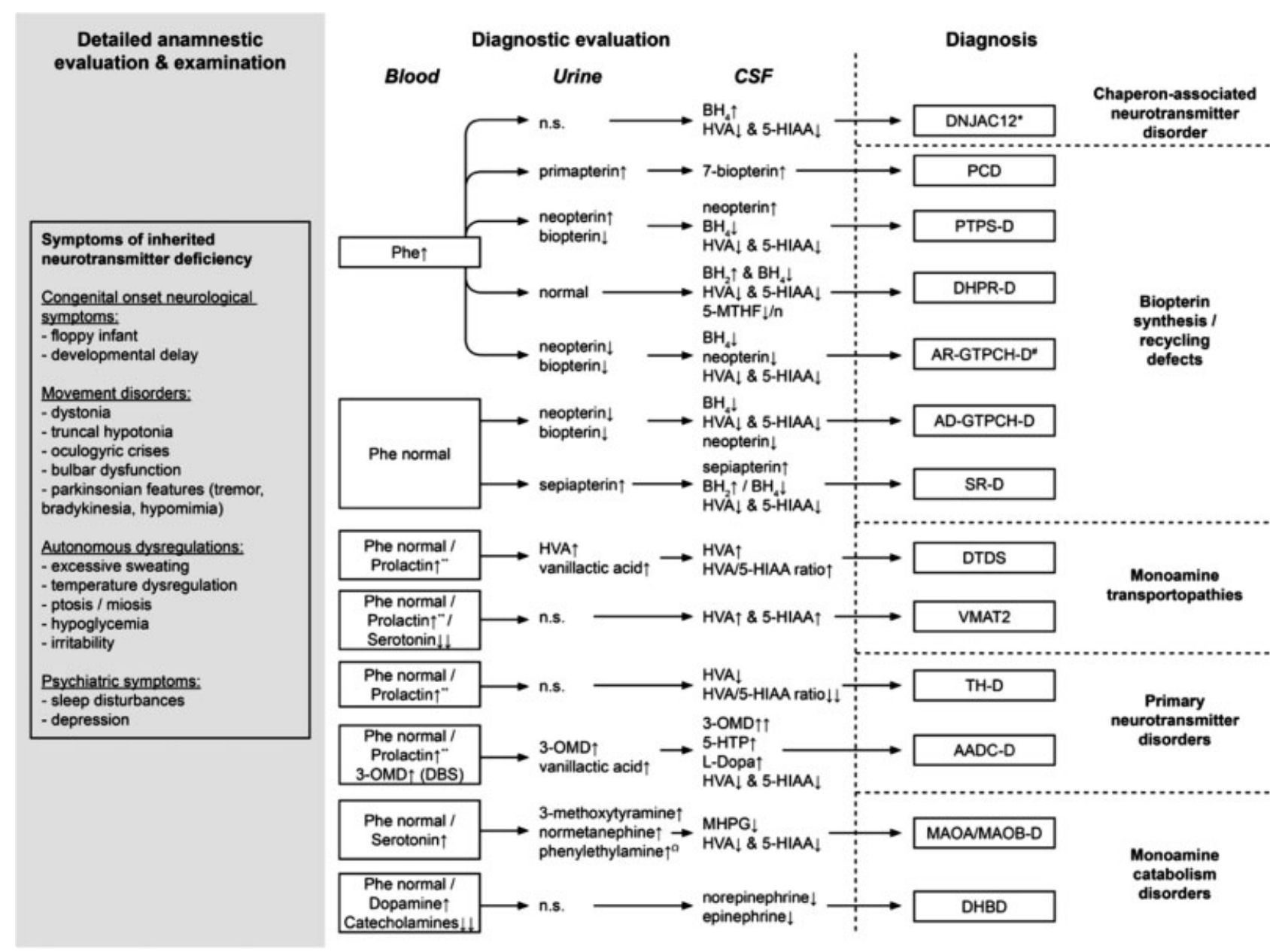

Fig. 2 Diagnostic flowchart for evaluation of inherited neurotransmitter diseases. Overview of the primary symptoms of inherited neurotransmitter diseases and a diagnostic flowchart for the analysis of blood, urine, and CSF. ( ${ }^{*}$ ) DNAJC12 encodes a heat shock co-chaperone of the HSP40 family which has been shown to interact with phenylalanine hydroxylase, tyrosine hydroxylase, and tryptophan hydroxylase catalyzing the respective hydroxylation. $\left({ }^{* *}\right)$ Elevated plasma levels of prolactin can be detected most probably due to central deficiency of dopamine due to its role as an inhibitor of prolactin release. $(\Omega)$ High levels of phenylethylamine in urine are only detected in MAOB deficient patients. (\#) Atypical presentations with normal Phe levels are possible. 3-OMD, 3-O-methyldopa; 5-HIAA, 5-hydroxyindoleacetic acid; 5-MTHF, methyltetrahydrofolate, $\mathrm{AADC}$, aromatic L-amino acid decarboxylase; $\mathrm{BH}_{2}, 7,8$-dihydroneopterin triphosphate; $\mathrm{BH}_{4}$, tetrahydrobiopterin; $\mathrm{DBS}$, dried blood spot; DHPR, dihydropterine reductase; DTDS, dopamine transport deficiency syndrome; GTPCH, Gganosine-5'-triphosphate cyclohydrolase; HVA, homovanillic acid; MAOA/B, monoamine oxidase A/B; MHPG, 3-methoxy-4-hydroxyphenylglycol; n.s., non-specific changes; PCD, pterin-4a-carbinolamine dehydratase; Phe, phenylalanine; PTPS, 6-pyruvoyltetrahydropterin synthase; SR, sepiapterin reductase; TH, tyrosine hydroxylase; VMAT 2, vesicular monoamine transporter 2

should be treated with antioxidative chemicals, special preservatives and stored in the absence of light. As there is a craniocaudal gradient in the concentrations of HVA and 5-HIAA, measurements should be performed in a standardized CSF volume fraction. ${ }^{86}$ The CSF analyses should always include pterins, 5-MTHF, and amino acids. According to the neurotransmitter pattern, sepiapterin analysis in CSF can be added. For all neurotransmitter disorders, biochemical findings can be confirmed by molecular genetic studies.

New technologies emerge to further utilize substrates such as blood and urine which are easier and less invasive to collect. In addition, high throughput next generation sequencing will help to accelerate the confirmation of a diagnosis and vastly expand our knowledge about new genotypes. If the diagnosis is established through genetic investigation in the first place (e.g., by whole exome sequen- cing or affected family member), functional confirmation should be added by measuring enzyme activity (in AADC-D) or measurement of neurotransmitter metabolites in CSF.

\section{Treatment}

A comprehensive overview of therapeutic options can be seen in - Table 1. Individual doses are subject to tolerance and the development of side effects.

A temporary therapeutic L-dopa trial has been used since many years in children or adults with unexplained earlyonset dystonia. This practice has been questioned in the very recent review in the view of tremendous advances in the pathophysiology of dystonia and the availably of highly sophisticated biochemical, radiological and molecular genetic investigations. ${ }^{87}$ According to the authors, a diagnostic L-dopa trial should be limited to children with the 
classical symptoms of dopa-responsive dystonia such as lower limb dystonia with diurnal variation or situations where deeper diagnostic is not available. If a trial of Ldopa is tried, we advocate for a detailed assessment of the current physical status including thorough (video supported) documentation of motor dysfunctions, autonomous dysregulations, and psychiatric symptoms.

In general, L-dopa treatment should be started at 0.5 to 1 $\mathrm{mg} / \mathrm{kg} / \mathrm{d}$ and be stepwise increased to a final dose of $10 \mathrm{mg} /$ $\mathrm{kg} / \mathrm{d}$ or the individual maximally tolerated dosage in at least four to five doses per day over a time period of 5 to 10 or more weeks. The pace of dosage increase depends on individual Ldopa sensitivity and on whether the patient is treated in an inpatient or in an outpatient setting (increases every 2-7 days). L-dopa should always be combined with a peripheral decarboxylase inhibitor (carbidopa or benserazide) in a $4: 1$ ratio. In contrast to patients with Parkinson's disease, neurotransmitter patients show no drug habituation and no need of increasing doses after years of therapy. The more profound dopamine deficiency symptoms are, the more likely an overreaction of the dopamine receptors such as choreatiform movement disorder, nausea, or vomiting may occur. These side effects may last for hours or a few days and are completely reversible. It was shown that L-dopa/carbidopa given at shorter intervals or as slow-release preparations has a higher chance to result in normal prolactin levels and clinical symptom relief compared with single doses with longer intervals; thus, this form should be preferred as soon as the total daily dose allows its use in (two or) three slowrelease dosages. ${ }^{88}$ It is possible that a longer period is needed for dystonia to improve; thus, stopping the L-dopa trial too early could cause false negative results. Therefore, around 2 months of treatment at $10 \mathrm{mg} / \mathrm{kg} /$ day or the individual maximally tolerated dosage are recommended to observe. If no improvement in motor function can be achieved over the trial period, L-dopa should be reduced stepwise over $\sim 4$ weeks. Total treatment time should not exceed $6(-8)$ months.

In pterin synthesis defects, serotonin needs to be substituted as well. The dose should generally be $\sim 2 \mathrm{mg} / \mathrm{kg} / \mathrm{d}$ less than L-dopa with a maximal dose of 8 to $10 \mathrm{mg} / \mathrm{kg} / \mathrm{d}$. Comparable to L-dopa, serotonin doses have to be titrated carefully. Side effects mostly comprise gastrointestinal discomfort. Overall, HPA can be treated with $\mathrm{BH}_{4}$ or PHE reduced diet. The desired target range for phenylalanine is below $6 \mathrm{mg} / \mathrm{dL}$ for all age groups. For PTPS and PCD deficiency, use of $\mathrm{BH}_{4}$ is recommended and in mild forms, might represent a sufficient monotherapy. As described above, currently, the use of $\mathrm{BH}_{4}$ in DHPR-D is under discussion. Here, diet should be the first line treatment of HPA. Folinic acid should always be supplemented in DHPR-D and in all other neurotransmitter disorders as soon as 5-MTHF in CSF has been documented to be low (10-20 mg/d).

\section{International Working Group on Neurotransmitter Related Disorders}

In 2013, an International Working Group on Neurotransmitter Related Disorders (iNTD). ${ }^{89}$ It currently consists of
43 partners from 24 different countries. The aim of this working group is to ultimately improve our understanding of the complex nature of inborn errors of neurotransmitter metabolism. Combining results of basic research and clinical data will hopefully improve our diagnostic tools, therapeutic approach, and thus, the quality of life of our patients. A web-based registry for inherited defects of biogenic amines, pterin, folate, serine, glycine, and GABA metabolism was established, which represents the first longitudinal register for neurotransmitter disorders. It enables systematic gathering of data in very high quality and so far, consists of data from more than 250 patients. A first consensus guideline on the diagnosis and treatment of AADC-D was published in 2017 and provides solid information and evidence-based clinical advice for practicing clinicians. $^{56}$

We are highly interested in further partners, metabolic centers, patients, and families who wish to participate. For further information visit www.intd-online.org.

\section{Model Systems for Basic Research on Neurotransmitter-Related Disorders}

Traditionally, the pathophysiology of human disease was studied with immortalized cell lines or in animal models. Unfortunately, animal models often do not exactly recapitulate human disease, and immortalized cells do not respond as their primary counterparts. ${ }^{90}$ Therefore, with the invention of reprogramming somatic cells into induced pluripotent cells (iPSCs) by Takahashi et al, a new patient-specific model system was introduced. ${ }^{91,92}$ In general, iPSCs resemble embryonic stem cells (ESCs), but circumvent the ethical issues associated with these cells. iPSCs are characterized by their unlimited self-renewal and the ability to differentiate into all cells of the three germ layers in two-dimensional (2D) and 3D organoid cultures. Therefore, since 2006 many disease-specific iPSCs have been generated including lines from patients suffering from neurotransmitter deficiencies. $^{93-95}$ These iPSCs can be differentiated to neuronal and glial cell types in 2D and to so-called cerebral "organoids" in $3 \mathrm{D}$, thereby mimicking embryonic brain development. ${ }^{96-98}$ Therefore, iPSCs not only represent a suitable model to study the underlying pathophysiology of the respective disease, but can also be used for drug screening approaches and cell replacement therapies. ${ }^{99}$ Besides cell culture models, also animal models for neurotransmitter-related disorders are available including knockout mice models for $\mathrm{TH}$ deficiency, ${ }^{100}$ SR deficiency, ${ }^{101}$ or DT deficiency. ${ }^{102}$

\section{Review Criteria}

PubMed was used to find English full-text articles published between January 1987 and July 2018 corresponding to the terms "monoamine," "neurotransmitter," "pediatric," and "deficiency." Articles were carefully read, and distinct reference articles were further investigated for clinically relevant research.

\section{Conflict of Interest}

None 


\section{Acknowledgments}

The work of the Neurotransmitter group at the Centre for Child and Adolescent Medicine in Heidelberg is supported in parts by the Dietmar Hopp Foundation (St. Leon-Rot, Germany) and SSADH-Defizit e.v.

\section{References}

1 Nestler EJ, Hyman SE, Holtzman DM, Malenka RC. Synaptic transmission. Molecular Neuropharmacology. Third ed. McGraw Hill; 2014

2 Kurian MA, Gissen P, Smith M, Heales S Jr, Clayton PT. The monoamine neurotransmitter disorders: an expanding range of neurological syndromes. Lancet Neurol 2011;10(08):721-733

3 Opladen T, Hoffmann GF, Blau N. An international survey of patients with tetrahydrobiopterin deficiencies presenting with hyperphenylalaninaemia. J Inherit Metab Dis 2012;35(06):963-973

4 Dekker SL, Kampinga HH, Bergink S. DNAJs: more than substrate delivery to HSPA. Front Mol Biosci 2015;2:35

5 Sarparanta J, Jonson PH, Golzio C, et al. Mutations affecting the cytoplasmic functions of the co-chaperone DNAJB6 cause limbgirdle muscular dystrophy. Nat Genet 2012;44(04):450-455, S1-S2

6 Crane BR, Arvai AS, Ghosh DK, et al. Structure of nitric oxide synthase oxygenase dimer with pterin and substrate. Science 1998;279(5359):2121-2126

7 Marras C, Lang A, van de Warrenburg BP, et al. Nomenclature of genetic movement disorders: recommendations of the International Parkinson and Movement Disorder Society task force. Mov Disord 2017;32(05):724-725

8 Nygaard TG. Dopa-responsive dystonia. Delineation of the clinical syndrome and clues to pathogenesis. Adv Neurol 1993;60:577-585

9 Goodchild RE, Grundmann K, Pisani A. New genetic insights highlight 'old' ideas on motor dysfunction in dystonia. Trends Neurosci 2013;36(12):717-725

10 López-Laso E, Ochoa-Sepúlveda JJ, Ochoa-Amor JJ, et al. Segawa syndrome due to mutation Q89X in the GCH1 gene: a possible founder effect in Córdoba (southern Spain). J Neurol 2009;256 (11):1816-1824

11 Segawa M, Nomura Y, Nishiyama N. Autosomal dominant guanosine triphosphate cyclohydrolase I deficiency (Segawa disease). Ann Neurol 2003;54(Suppl 6):S32-S45

12 Bandmann O, Wood NW. Dopa-responsive dystonia - the story so far. Neuropediatrics 2002;33(01):1-5

13 López-Laso E, Sánchez-Raya A, Moriana JA, et al. Neuropsychiatric symptoms and intelligence quotient in autosomal dominant Segawa disease. J Neurol 2011;258(12):2155-2162

14 Nygaard TG, Marsden CD, Fahn S. Dopa-responsive dystonia: long-term treatment response and prognosis. Neurology 1991; 41(2 (Pt 1)):174-181

15 Tadic V, Kasten M, Brüggemann N, Stiller S, Hagenah J, Klein C. Dopa-responsive dystonia revisited: diagnostic delay, residual signs, and nonmotor signs. Arch Neurol 2012;69(12):1558-1562

16 Thöny B, Blau N. Mutations in the BH4-metabolizing genes GTP cyclohydrolase I, 6-pyruvoyl-tetrahydropterin synthase, sepiapterin reductase, carbinolamine-4a-dehydratase, and dihydropteridine reductase. Hum Mutat 2006;27(09):870-878

17 Friedman J, Roze E, Abdenur JE, et al. Sepiapterin reductase deficiency: a treatable mimic of cerebral palsy. Ann Neurol 2012; 71(04):520-530

18 Friedman J. Sepiapterin Reductase Deficiency. In: Adam MP, Ardinger HH, Pagon RA, et al., eds. GeneReviews ${ }^{\circledR}$ [Internet]. Seattle, WA: University of Washington; 1993-2018. Available at: https://www.ncbi.nlm.nih.gov/books/NBK304122/. Accessed October 1, 2018

19 Abeling NG, Duran M, Bakker HD, et al. Sepiapterin reductase deficiency an autosomal recessive DOPA-responsive dystonia. Mol Genet Metab 2006;89(1-2):116-120
20 Friedman J, Hyland K, Blau N, MacCollin M. Dopa-responsive hypersomnia and mixed movement disorder due to sepiapterin reductase deficiency. Neurology 2006;67(11):2032-2035

21 Leuzzi V, Carducci C, Tolve M, Giannini MT, Angeloni A, Carducci C. Very early pattern of movement disorders in sepiapterin reductase deficiency. Neurology 2013;81(24):2141-2142

22 Neville BG, Parascandalo R, Farrugia R, Felice A. Sepiapterin reductase deficiency: a congenital dopa-responsive motor and cognitive disorder. Brain 2005;128(Pt 10):2291-2296

23 Zielonka M, Makhseed N, Blau N, Bettendorf M, Hoffmann GF, Opladen T. Dopamine-responsive growth-hormone deficiency and central hypothyroidism in sepiapterin reductase deficiency. JIMD Rep 2015;24:109-113

24 Carducci C, Santagata S, Friedman J, et al. Urine sepiapterin excretion as a new diagnostic marker for sepiapterin reductase deficiency. Mol Genet Metab 2015;115(04):157-160

25 Opladen T, Hoffmann G, Hörster F, et al. Clinical and biochemical characterization of patients with early infantile onset of autosomal recessive GTP cyclohydrolase I deficiency without hyperphenylalaninemia. Mov Disord 2011;26(01):157-161

26 Horvath GA, Stockler-Ipsiroglu SG, Salvarinova-Zivkovic R, et al. Autosomal recessive GTP cyclohydrolase I deficiency without hyperphenylalaninemia: evidence of a phenotypic continuum between dominant and recessive forms. Mol Genet Metab 2008; 94(01):127-131

27 Niederwieser A, Shintaku H, Leimbacher W, et al. "Peripheral" tetrahydrobiopterin deficiency with hyperphenylalaninaemia due to incomplete 6-pyruvoyl tetrahydropterin synthase deficiency or heterozygosity. Eur J Pediatr 1987; 146(03):228-232

28 Blau N, Thöny B, Cotton RGH, et al. Disorders of tetrahydrobiopterin and related biogenic amines. In: Scriver CR, Beaudet AL, Sly WS et al., ed. The Metabolic and Molecular Bases of Inherited Disease. New York, NY: McGraw-Hill; 2001:1725-1776

29 Leuzzi V, Carducci CA, Carducci CL, et al. Phenotypic variability, neurological outcome and genetics background of 6-pyruvoyltetrahydropterin synthase deficiency. Clin Genet 2010;77(03): 249-257

30 Werner ER, Blau N, Thöny B. Tetrahydrobiopterin: biochemistry and pathophysiology. Biochem J 2011;438(03):397-414

31 Ponzone A, Spada M, Ferraris S, Dianzani I, de Sanctis L. Dihydropteridine reductase deficiency in man: from biology to treatment. Med Res Rev 2004;24(02):127-150

32 Longo N. Disorders of biopterin metabolism. J Inherit Metab Dis 2009;32(03):333-342

33 Ramaekers VT, Blau N. Cerebral folate deficiency. Dev Med Child Neurol 2004;46(12):843-851

34 Gasnier B. The loading of neurotransmitters into synaptic vesicles. Biochimie 2000;82(04):327-337

35 Hyland K, Shoffner J, Heales SJ. Cerebral folate deficiency. J Inherit Metab Dis 2010;33(05):563-570

36 Coughlin CR II, Hyland K, Randall R, Ficicioglu C. Dihydropteridine reductase deficiency and treatment with tetrahydrobiopterin: a case report. JIMD Rep 2013;10:53-56

37 Irons M, Levy HL, O'Flynn ME, et al. Folinic acid therapy in treatment of dihydropteridine reductase deficiency. J Pediatr 1987;110(01):61-67

38 Thöny B, Neuheiser F, Kierat L, et al. Mutations in the pterin4alpha-carbinolamine dehydratase (PCBD) gene cause a benign form of hyperphenylalaninemia. Hum Genet 1998;103(02): $162-167$

39 Rhee KH, Stier G, Becker PB, Suck D, Sandaltzopoulos R. The bifunctional protein $\mathrm{DCoH}$ modulates interactions of the homeodomain transcription factor HNF1 with nucleic acids. J Mol Biol 1997;265(01):20-29

40 Mendel DB, Khavari PA, Conley PB, et al. Characterization of a cofactor that regulates dimerization of a mammalian homeodomain protein. Science 1991;254(5039):1762-1767 
41 Simaite D, Kofent J, Gong M, et al. Recessive mutations in PCBD1 cause a new type of early-onset diabetes. Diabetes 2014;63(10): 3557-3564

42 Willemsen MA, Verbeek MM, Kamsteeg EJ, et al. Tyrosine hydroxylase deficiency: a treatable disorder of brain catecholamine biosynthesis. Brain 2010;133(Pt 6):1810-1822

43 Pons R, Syrengelas D, Youroukos S, et al. Levodopa-induced dyskinesias in tyrosine hydroxylase deficiency. Mov Disord 2013;28(08):1058-1063

44 Marín-Valencia I, Serrano M, Ormazabal A, et al. Biochemical diagnosis of dopaminergic disturbances in paediatric patients: analysis of cerebrospinal fluid homovanillic acid and other biogenic amines. Clin Biochem 2008;41(16-17):1306-1315

45 Hoffmann GF, Assmann B, Bräutigam C, et al. Tyrosine hydroxylase deficiency causes progressive encephalopathy and dopanonresponsive dystonia. Ann Neurol 2003;54(Suppl 6):S56-S65

46 Yeung WL, Wong VC, Chan KY, et al. Expanding phenotype and clinical analysis of tyrosine hydroxylase deficiency. J Child Neurol 2011;26(02):179-187

47 Lee HF, Tsai CR, Chi CS, Chang TM, Lee HJ. Aromatic L-amino acid decarboxylase deficiency in Taiwan. Eur J Paediatr Neurol 2009; 13(02):135-140

48 Mastrangelo M, Caputi C, Galosi S, Giannini MT, Leuzzi V. Transdermal rotigotine in the treatment of aromatic L-amino acid decarboxylase deficiency. Mov Disord 2013;28(04): 556-557

49 Brun L, Ngu LH, Keng WT, et al. Clinical and biochemical features of aromatic L-amino acid decarboxylase deficiency. Neurology 2010;75(01):64-71

50 Swoboda KJ, Hyland K, Goldstein DS, et al. Clinical and therapeutic observations in aromatic L-amino acid decarboxylase deficiency. Neurology 1999;53(06):1205-1211

51 Haavik J, Blau N, Thöny B. Mutations in human monoaminerelated neurotransmitter pathway genes. Hum Mutat 2008;29 (07):891-902

52 Hyland K, Surtees RA, Rodeck C, Clayton PT. Aromatic L-amino acid decarboxylase deficiency: clinical features, diagnosis, and treatment of a new inborn error of neurotransmitter amine synthesis. Neurology 1992;42(10):1980-1988

53 Wassenberg T, Monnens LA, Geurtz BP, Wevers RA, Verbeek MM, Willemsen MA. The paradox of hyperdopaminuria in aromatic L-amino acid deficiency explained. JIMD Rep 2012;4:39-45

54 Atwal PS, Donti TR, Cardon AL, et al. Aromatic L-amino acid decarboxylase deficiency diagnosed by clinical metabolomic profiling of plasma. Mol Genet Metab 2015;115(2-3):91-94

55 Bräutigam C, Hyland K, Wevers R, et al. Clinical and laboratory findings in twins with neonatal epileptic encephalopathy mimicking aromatic L-amino acid decarboxylase deficiency. Neuropediatrics 2002;33(03):113-117

56 Wassenberg T, Molero-Luis M, Jeltsch K, et al. Consensus guideline for the diagnosis and treatment of aromatic l-amino acid decarboxylase (AADC) deficiency. Orphanet J Rare Dis 2017;12(01):12

57 Hwu WL, Muramatsu S, Tseng SH, et al. Gene therapy for aromatic L-amino acid decarboxylase deficiency. Sci Transl Med 2012;4(134):134ra61

58 Chang YT, Sharma R, Marsh JL, et al. Levodopa-responsive aromatic L-amino acid decarboxylase deficiency. Ann Neurol 2004;55(03):435-438

59 Brunner HG, Nelen M, Breakefield XO, Ropers HH, van Oost BA. Abnormal behavior associated with a point mutation in the structural gene for monoamine oxidase A. Science 1993;262 (5133):578-580

60 Cheung NW, Earl J. Monoamine oxidase deficiency: a cause of flushing and attention-deficit/hyperactivity disorder? Arch Intern Med 2001;161(20):2503-2504

61 Schuback DE, Mulligan EL, Sims KB, et al. Screen for MAOA mutations in target human groups. Am J Med Genet 1999;88 (01):25-28
62 Whibley A, Urquhart J, Dore J, et al. Deletion of MAOA and MAOB in a male patient causes severe developmental delay, intermittent hypotonia and stereotypical hand movements. Eur J Hum Genet 2010;18(10):1095-1099

63 Lenders JW, Eisenhofer G, Abeling NG, et al. Specific genetic deficiencies of the $A$ and $B$ isoenzymes of monoamine oxidase are characterized by distinct neurochemical and clinical phenotypes. J Clin Invest 1996;97(04):1010-1019

64 Abeling NG, van Gennip AH, Overmars H, van Oost BA, Brunner HG. Biogenic amine metabolite patterns in the urine of monoamine oxidase A-deficient patients. A possible tool for diagnosis. J Inherit Metab Dis 1994;17(03):339-341

65 Brunner HG, Nelen MR, van Zandvoort P, et al. X-linked borderline mental retardation with prominent behavioral disturbance: phenotype, genetic localization, and evidence for disturbed monoamine metabolism. Am J Hum Genet 1993;52(06):1032-1039

66 Godar SC, Bortolato M, Castelli MP, et al. The aggression and behavioral abnormalities associated with monoamine oxidase $\mathrm{A}$ deficiency are rescued by acute inhibition of serotonin reuptake. J Psychiatr Res 2014;56:1-9

67 Robertson D, Garland EM. Dopamine beta-hydroxylase deficiency. In: Adam MP, Ardinger HH, Pagon RA, et al., eds. GeneReviews ${ }^{\circledR}$ [Internet]. Seattle, WA: University of Washington; 1993-2018. Available at: https://www.ncbi.nlm.nih.gov/ books/NBK1474/. Accessed October 1, 2018

68 Ste Marie L, Palmiter RD. Norepinephrine and epinephrinedeficient mice are hyperinsulinemic and have lower blood glucose. Endocrinology 2003;144(10):4427-4432

69 Arnold AC, Garland EM, Celedonio JE, et al. Hyperinsulinemia and insulin resistance in dopamine $\beta$-hydroxylase deficiency. J Clin Endocrinol Metab 2017;102(01):10-14

70 Timmers HJ, Deinum J, Wevers RA, Lenders JW. Congenital dopamine-beta-hydroxylase deficiency in humans. Ann N Y Acad Sci 2004;1018:520-523

71 van den Berg MP, Almomani R, Biaggioni I, et al. Mutations in CYB561 causing a novel orthostatic hypotension syndrome. Circ Res 2018;122(06):846-854

72 Ford $\mathrm{CP}$. The role of D2-autoreceptors in regulating dopamine neuron activity and transmission. Neuroscience 2014;282:13-22

73 Kurian MA, Li Y, Zhen J, et al. Clinical and molecular characterisation of hereditary dopamine transporter deficiency syndrome: an observational cohort and experimental study. Lancet Neurol 2011;10(01):54-62

$74 \mathrm{Ng} \mathrm{J}$, Zhen J, Meyer E, et al. Dopamine transporter deficiency syndrome: phenotypic spectrum from infancy to adulthood. Brain 2014;137(Pt 4):1107-1119

75 Yildiz Y, Pektas E, Tokatli A, Haliloglu G. Hereditary dopamine transporter deficiency syndrome: challenges in diagnosis and treatment. Neuropediatrics 2017;48(01):49-52

76 Rilstone JJ, Alkhater RA, Minassian BA. Brain dopamine-serotonin vesicular transport disease and its treatment. $\mathrm{N}$ Engl J Med 2013;368(06):543-550

77 Rath M, Korenke GC, Najm J, et al. Exome sequencing results in identification and treatment of brain dopamine-serotonin vesicular transport disease. J Neurol Sci 2017;379:296-297

$78 \mathrm{Ng}$ J, Heales SJ, Kurian MA. Clinical features and pharmacotherapy of childhood monoamine neurotransmitter disorders. Paediatr Drugs 2014;16(04):275-291

79 Anikster Y, Haack TB, Vilboux T, et al. Biallelic mutations in DNAJC12 cause hyperphenylalaninemia, dystonia, and intellectual disability. Am J Hum Genet 2017;100(02):257-266

80 Blau N, Martinez A, Hoffmann GF, Thöny B. DNAJC12 deficiency: a new strategy in the diagnosis of hyperphenylalaninemias. Mol Genet Metab 2018;123(01):1-5

81 Straniero L, Guella I, Cilia R, et al. DNAJC12 and dopa-responsive nonprogressive parkinsonism. Ann Neurol 2017;82(04):640-646

82 Katus LE, Frucht SJ. An unusual presentation of tyrosine hydroxylase deficiency. J Clin Mov Disord 2017;4:18 
83 Woody RC, Brewster MA, Glasier C. Progressive intracranial calcification in dihydropteridine reductase deficiency prior to folinic acid therapy. Neurology 1989;39(05):673-675

84 Coşkun T, Besim A, Ozalp I, Eryilmaz M. Intracranial calcification in dihydropteridine reductase deficiency. Turk J Pediatr 1990;32 (04):259-264

85 Smit M, Bartels AL, van Faassen M, et al. Serotonergic perturbations in dystonia disorders-a systematic review. Neurosci Biobehav Rev 2016;65:264-275

86 Hoffmann GF, Blau N. Congenital Neurotransmitter Disorders: A Clinical Approach. Nova Science Publishers; 2014

87 Maas RPPWM, Wassenberg T, Lin JP, van de Warrenburg BPC, Willemsen MAAP. 1-Dopa in dystonia: a modern perspective. Neurology 2017;88(19):1865-1871

88 Birnbacher R, Scheibenreiter S, Blau N, Bieglmayer C, Frisch H, Waldhauser F. Hyperprolactinemia, a tool in treatment control of tetrahydrobiopterin deficiency: endocrine studies in an affected girl. Pediatr Res 1998;43(4 Pt 1):472-477

89 Opladen T, Cortès-Saladelafont E, Mastrangelo M, et al; International Working Group on Neurotransmitter related disorders (iNTD). The International Working Group on Neurotransmitter related Disorders (iNTD): a worldwide research project focused on primary and secondary neurotransmitter disorders. Mol Genet Metab Rep 2016;9:61-66

90 Perlman RL. Mouse models of human disease: an evolutionary perspective. Evol Med Public Health 2016;2016(01):170-176

91 Takahashi K, Yamanaka S. Induction of pluripotent stem cells from mouse embryonic and adult fibroblast cultures by defined factors. Cell 2006;126(04):663-676

92 Takahashi K, Tanabe K, Ohnuki M, et al. Induction of pluripotent stem cells from adult human fibroblasts by defined factors. Cell 2007;131(05):861-872

93 Jung-Klawitter S, Blau N, Sebe A, Ebersold J, Göhring G, Opladen T. Generation of an iPSC line from a patient with tyrosine hydroxylase (TH) deficiency: TH-1 iPSC. Stem Cell Res (Amst) 2016;17(03):580-583

94 Jung-Klawitter S, Ebersold J, Göhring G, Blau N, Opladen T. Generation of an iPSC line from a patient with GTP cyclohydrolase 1 (GCH1) deficiency: HDMC0061i-GCH1. Stem Cell Res (Amst) 2017;20:38-41

95 Ishikawa T, Imamura K, Kondo T, et al. Genetic and pharmacological correction of aberrant dopamine synthesis using patient iPSCs with BH4 metabolism disorders. Hum Mol Genet 2016;25 (23):5188-5197

96 Lancaster MA, Renner M, Martin CA, et al. Cerebral organoids model human brain development and microcephaly. Nature 2013;501(7467):373-379

97 Qian X, Nguyen HN, Song MM, et al. Brain-region-specific organoids using mini-bioreactors for modeling ZIKV exposure. Cell 2016;165(05):1238-1254

98 Muguruma K, Nishiyama A, Kawakami H, Hashimoto K, Sasai Y. Self-organization of polarized cerebellar tissue in 3D culture of human pluripotent stem cells. Cell Reports 2015;10(04): 537-550

99 Jung-Klawitter S, Opladen T. Induced pluripotent stem cells (iPSCs) as model to study inherited defects of neurotransmission in inborn errors of metabolism. J Inherit Metab Dis 2018

100 Korner G, Noain D, Ying M, et al. Brain catecholamine depletion and motor impairment in a Th knock-in mouse with type B tyrosine hydroxylase deficiency. Brain 2015;138(Pt 10):2948-2963

101 Takazawa C, Fujimoto K, Homma D, et al. A brain-specific decrease of the tyrosine hydroxylase protein in sepiapterin reductase-null mice-as a mouse model for Parkinson's disease. Biochem Biophys Res Commun 2008;367(04):787-792

102 Salvatore MF, Calipari ES, Jones SR. Regulation of tyrosine hydroxylase expression and phosphorylation in dopamine transporterdeficient mice. ACS Chem Neurosci 2016;7(07):941-951 